\title{
Isolation, purification and characterization of Trichothecinol-A produced by endophytic fungus Trichothecium sp. and its antifungal, anticancer and antimetastatic activities
}

Ravindra Taware ${ }^{1}$, Prasad Abnave ${ }^{1}$, Deepak Patil ${ }^{2}$, Pattuparambil Ramanpillai Rajamohananan ${ }^{2}$, Remya Raja ${ }^{3}$, Gowrishankar Soundararajan ${ }^{3}$, Gopal Chandra Kundu ${ }^{3}$ and Absar Ahmad ${ }^{1 *}$

\begin{abstract}
Background: A total of 30 endophytic fungi (AAP-PS 1-30) were isolated from the medicinal herb Phyllanthus amarus and screened for the production of Trichothecinol-A. Out of all the endophytic strains screened for Trichothecinol-A production, the culture filtrate of AAP-PS-1 extracted with ethyl acetate yielded Trichothecinol-A extracellularly in appreciable amounts. Trichothecinol-A was purified, quantified and completely characterized by different standard chromatographic and spectroscopic techniques including reverse phase HPLC, 1D and 2D NMR spectroscopy, etc. The compound was tested for antifungal activity against filamentous fungi and yeast, apoptotic activity against B16F10 cells, anticancer activity against MDA-MB-231, HeLa and B16F10 cells as well as antimetastatic activity against MDA-MB-231 cell line.

Results: The endophyte producing Trichothecinol-A was identified as Trichothecium sp. by morphological, cultural and molecular methods. RP-HPLC analyses performed on a Waters model using a $C_{18}$ symmetry pack column with a flow rate of $0.5 \mathrm{ml} / \mathrm{min}$ and the eluting compounds were detected by a dual mode wavelength detector set at $220 \mathrm{~nm}$ and $240 \mathrm{~nm}$. The $1 \mathrm{D}\left({ }^{1} \mathrm{H},{ }^{13} \mathrm{C}\right)$ and 2D NMR (COSY, NOESY, TOCSY, DEPT, $\left.{ }^{13} \mathrm{C}-{ }^{1} \mathrm{H} \mathrm{HMBC},{ }^{13} \mathrm{C}-{ }^{1} \mathrm{H} H S Q C\right)$, ESI-MS, HRMS, IR and UV-vis show conclusively that the isolated compound was Trichothecinol-A. One liter of Trichothecium sp. yielded $4.37 \mathrm{mg}$ of Trichothecinol-A. Trichothecinol-A exhibited antifungal activity against Cryptococcus albidus (NCIM 3372) up to $20 \mu \mathrm{g} / \mathrm{ml}$. Cytotoxicity studies indicate that Trichothecinol-A causes 50\% cell death at 500nM concentration in HeLa and B16F10 cells and induces apoptosis in later. Inhibition of wound migration assay performed on MDA-MB-231 cells reveals that 500nM of Trichothecinol-A was able to inhibit wound migration by $50 \%$ indicating its remarkable antimetastatic property.

Conclusion: The compound Trichothecinol-A has previously been isolated from Trichothecium roseum and characterized by various standard techniques. Anti-cancer studies conducted on Trichothecinol-A showed that it significantly inhibits cancer cell migration and can thus be developed as a new class of anti-metastatic drug. Here, we for the first time report the anti-metastatic as well as anti-fungal activity exhibited by Trichothecinol-A isolated by us from the endophytic fungus Trichothecium sp. of medicinal plant Phyllanthus amarus. Trichothecinol-A also exhibited apoptotic activity.
\end{abstract}

Keywords: Trichothecinol-A, Trichothecium sp., Antimetastatic, Antiproliferative, Cancer cell migration, Antifungal

\footnotetext{
* Correspondence: a.ahmad@ncl.res.in

'Division of Biochemical Sciences, CSIR-National Chemical Laboratory, Dr. Homi Bhabha Road, Pune 411008, India

Full list of author information is available at the end of the article
}

\section{() Chemistry Central}

(c) 2014 Taware et al.; licensee Chemistry Central Ltd. This is an Open Access article distributed under the terms of the Creative Commons Attribution License (http://creativecommons.org/licenses/by/2.0), which permits unrestricted use, distribution, and reproduction in any medium, provided the original work is properly credited. The Creative Commons Public Domain Dedication waiver (http://creativecommons.org/publicdomain/zero/1.0/) applies to the data made available in this article, unless otherwise stated. 


\section{Background}

Endophytic fungi are microorganisms which spend the whole or part of their life-cycle residing symbiotically within the healthy tissues of host plants, inter-and/or intra-cellularly and produce bioactive natural products or drugs and derivatives; meanwhile causing no damage or disease to their hosts [1].

Owing to the huge developments in the fields of genetic engineering, microbial fermentation technology, etc. the past two decades have seen a major increase in the number of researchers working hard to explore the endophytic fungal diversity, and better understand the relationships between endophytic fungi and their host plants, in an attempt to employ endophytes to obtain valuable compounds of plant origin without exploiting plant parts and to improve the productivity of the ones already being derived by optimizing fermentation conditions to reap benefits of abundant renewable supply $[2,3]$. Thus, endophytes hold tremendous promise as an alternative eco-friendly source for efficiently producing valuable bioactive compounds in the future with varied applications in both the research and applied fields of medicine, food industry, agriculture, pest management, etc.

Trichothecenes are a vast group of structurally and chemically related mycotoxins which have a strong impact on the health and well-being of humans, plants and farm animals. These mycotoxins are complex sesquiterpene secondary metabolites produced by fungi belonging to various species of Fusarium, Trichothecium, Trichoderma, Myrothecium, Cephalosporium, Stachybotrys, etc. These mycotoxins are highly stable even during the milling, processing and cooking of food stuffs and thus it's very difficult to get rid of them $[4,5]$. It is these trichothecenes which are responsible for the toxicity and spoilage of grains, fruits, vegetables, tubers and other vegetative products worldwide.

Trichothecenes are minute, amphiphatic molecules which are extremely powerful inhibitors of protein synthesis as these have their specific site of action located on a very crucial site on the ribosomal RNA (rRNA), thus interfering with the normal polypeptide chain initiation, elongation and termination [6,7]. Altering the biological activity of trichothecenes has helped in inducing anti-bacterial, anti-viral, insecticidal, phytotoxic, cytoxic, anti-biotic and anti-tumour properties in the resultant molecules [8]. Konishi et al. reported the trichothecinols $\mathrm{A}-\mathrm{C}$, all showing remarkable potential at inhibiting EBV-EA activation induced by TPA (12-O-tetradecanoylphorbol-13-acetate) in Raji cells [9]. Out of these, the most active compound, Trichothecinol-A also suppressed TPA-induced tumour promotion on mouse skin initiated with DMBA (7,12-dimethylbenz[a]anthracene) in a two-stage carcinogenesis experiment.
As part of our ongoing research for plant based drugs using endophytic fungi, we started the isolation and screening of endophytic fungi from medicinal herb Phyllanthus amarus for the production of various beneficial bioactive secondary metabolites and identified a fungal strain Trichothecium sp. which during the present investigation produced only antifungal secondary metabolites against Aspergillus niger. The compound was identified as sesquiterpenoid trichothecene mycotoxin and completely characterized as Trichothecinol-A. P. amarus was used as it is a known astringent, deobstruent, stomachic, diuretic, febrifugal, antiseptic, employed in dropsy and diseases of urinogenital system; its leaves are expectorant, diaphoretic; seeds are carminative, laxative, astringent to the bowels, tonic to the liver, and used as a remedy for bronchitis, earache, griping, opthalmia and ascites [10-13]. Fresh roots and leaves of this plant have also been reported to be potent remedy for jaundice. All these features made $P$. amarus a very worthy candidate for our study.

The present work focuses on the isolation, purification and complete characterization of Trichothecinol-A from the endophytic fungus Trichothecium sp. isolated from $P$. amarus. The anti-fungal, anti-cancer (anti-proliferative), anti-metastatic and apoptotic activities of trichothecinol-A revealed its class-apart potential to be developed as a drug for each mentioned field.

\section{Results and discussion}

\section{Isolation, purification and identification of endophytic fungus producing Trichothecinol-A}

Total thirty endophytic fungi were isolated from leaves and stems of $P$. amarus and only one culture (AAPPS-1) isolated from leaves was found to produce Trichothecinol-A extracellularly. Trichothecinol-A producing fungal culture was identified using molecular and morphological approaches. Morphological observations revealed that conidiophores were long, slender, simple, bearing conidia singly, apically, sometimes held together in groups or chains; conidia were hyaline, 2-celled and ovoid to ellipsoid.

Amplification of fungal genomic DNA by primers ITS1 and ITS4 yielded 650 bps fragment (Accession No. JN603460). The analysis of sequence revealed 99.9\% identity with that of Trichothecium roseum. Phylogenetic analysis of this strain AAP-PS-1 based on ITS sequences exhibited $98 \%$ nucleotide sequence similarity with Trichothecium roseum, the phylogenetically closest validated genus (Figure 1). The ITS sequence analysis and homology alignment of isolate AAP-PS-1 using BLAST and Clustal-W programme respectively revealed similarity with $T$. roseum. Also, morphological and cultural studies confirm that the isolate belongs to genus Trichothecium [14]. 


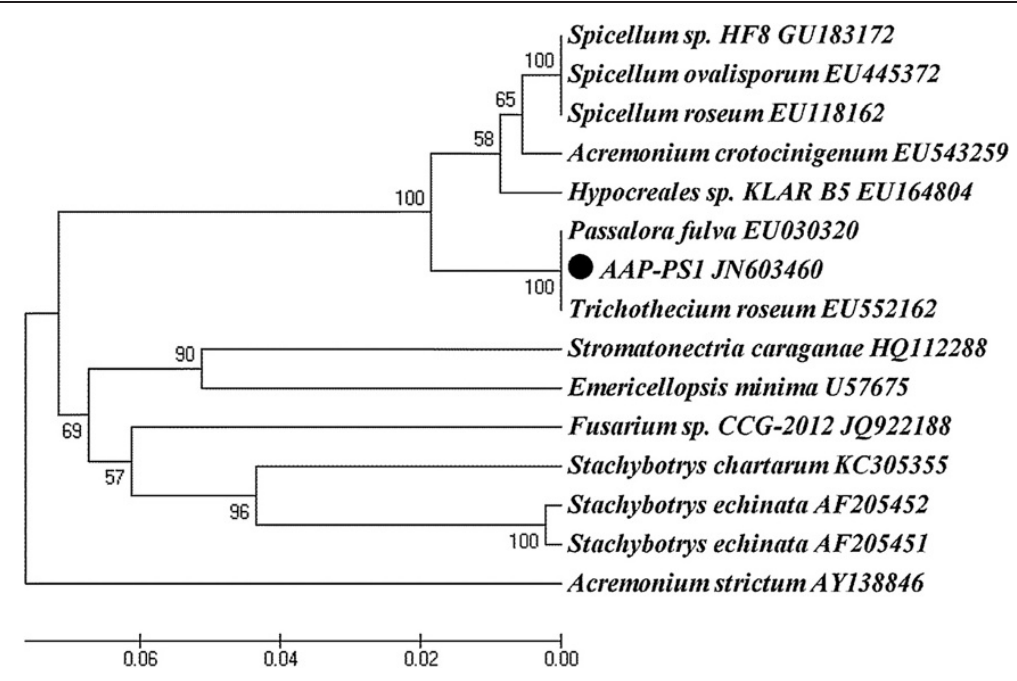

Figure 1 Phylogenetic tree highlighting the position of Trichothecium sp. within the closely related genus. GenBank accession numbers are indicated in parentheses. The scale bar represents a 5\% nucleotide sequence divergence.

Purification, quantification and complete characterization of Trichothecinol-A

Purified Trichothecinol-A eluted at retention time of 34 minutes when loaded on analytical $\mathrm{C}_{18}$ symmetry pack column with a flow rate of $0.5 \mathrm{~mL} / \mathrm{min}$. EtoAc extract of one litre of filterate of Trichothecium sp. fermented in modified S7 medium yielded $4.37 \mathrm{mg}$ of Trichothecinol-A. Maximum UV absorption was recorded at $251 \mathrm{~nm}$ in ethyl acetate. The mass spectrum showed molecular ion at $\mathrm{m} / z 349.57$ and at $\mathrm{m} / z 371.28$ attributing to $\mathrm{M}+\mathrm{H}$ and $\mathrm{M}+\mathrm{Na}$ ions of TrichothecinolA respectively. The HRMS spectrum showed molecular ion at 348.0683 attributing to ions of Trichothecinol-A $\left(\mathrm{C}_{19} \mathrm{H}_{24} \mathrm{O}_{6}\right)$. The FTIR spectrum showed characteristic bands of Trichothecinol-A at 1679, 1721 and $3452 \mathrm{~cm}^{-1}$. (HPLC details, UV-visible spectroscopy measurements, FTIR spectroscopy measurements, ESI-MS details are included as supporting information (Additional file 1: Figure S1 - S4).

The ${ }^{1} \mathrm{H}$ NMR spectrum of the Trichothecinol-A showed the presence of 24 protons with the olefinic peaks in side chain ester linkage at $\sim 6.48 \delta, 5.89 \delta$ and the ring olefinic proton at $\sim 6.60 \delta$. The methyl groups (Me 14, 15, 16 and 20) appeared at $\sim 0.76 \delta, \sim 1.03 \delta, \sim 1.83 \delta$ and $\sim 2.17 \delta$, respectively. The protons of epoxide methylene group (13a, $13 \mathrm{~b})$ appeared as doublets at $\sim 2.81 \delta$ and $\sim 3.08 \delta$. The other methylene group $(7 \mathrm{a}, 7 \mathrm{~b})$ resonated at $\sim 2.33 \delta$ and $\sim 2.96 \delta$. The most noticeable feature of the ${ }^{1} \mathrm{H}$ spectrum is the presence of a broad peak at $\sim 3.48 \delta$ which belongs to $\mathrm{OH}$ group proton. ${ }^{13} \mathrm{C}$ NMR spectrum showed the presence of 19 carbons which included two carbonyls $(198.52 \delta, 168.05 \delta)$, four olefinic ( $148 \delta$ to $119 \delta)$ and thirteen $\mathrm{sp}^{3}$ carbons in the region $85 \delta$ to $5 \delta$. The assignments of the ${ }^{1} \mathrm{H}$ and ${ }^{13} \mathrm{C}$ spectra are presented in Table 1 and Figure 2. The spectral details are included as Supporting information (Additional file 1: Figures S5-S12, Tables S1 and S2). The NMR spectral features are found to match very well with the one reported by Konishi et al. [9].

\section{Antifungal activity of Trichothecinol-A}

In contrary to earlier reports [9], we for the first time demonstrated antifungal activity of Trichothecinol-A against a range of filamentous fungi and yeast. Trichothecinol-A exhibited moderate activity against yeast Cryptococcus albidus var diffluens NCIM 3372 up to $20 \mu \mathrm{g} / \mathrm{mL}$. MIC and $\mathrm{IC}_{50}$ values were determined as described below (Table 2). Dose response curves of Trichothecinol-A are included as supporting information (Additional file 1: Figure S13).

\section{Trichothecinol-A exhibit cytotoxicity at nanomolar} concentrations against B16F10 and HeLa cells and effectively inhibit cell migration in MDA-MB-231 cells Cytotoxicity studies indicated that B16F10 and HeLa cells show enhanced sensitivity to Trichothecinol-A compared to MDA-MB-231 cells. Trichothecinol-A induced about 50\% cell death in HeLa and B16F10 cells compared to about 25\% in MDA-MB-231 cells at 500 nM concentrations (Figure 3).

The effect of Trichothecinol-A on B16F10 cell death was performed by cell cycle analysis. Briefly, cells were treated with Trichothecinol-A in a dose of $0-5 \mu \mathrm{M}$ for 12 and $24 \mathrm{~h}$ respectively and then stained with PI (propidium iodide). The DNA fluorescence histogram of PI-stained cells revealed a distinct quantifiable region beyond G1 peak (Figure 4). 
Table $1{ }^{1} \mathrm{H}$ and ${ }^{13} \mathrm{C}$ NMR assignments* of Trichothecinol-A

\begin{tabular}{|c|c|c|}
\hline Position & $\delta^{1} \mathrm{H}\left(J_{\mathrm{HH}}\right) \mathrm{Hz}$ & $\delta{ }^{13} \mathrm{C}$ \\
\hline 2 & $3.80(4.95)$ & 79.31 \\
\hline \multirow[t]{2}{*}{3} & $4.27(4.95,3.00)$ & 78.93 \\
\hline & $\mathrm{OH}-3.48, \mathrm{br}$ & \\
\hline 4 & $4.93(3.00)$ & 83.38 \\
\hline 5 & & 48.87 \\
\hline 6 & & 44.71 \\
\hline $7 a$ & $2.33(15.18,1.54)$ & 42.06 \\
\hline $7 b$ & $2.96,(15.18,1.10)$ & \\
\hline 8 & & 198.52 \\
\hline 9 & & 137.52 \\
\hline 10 & $6.60(5.80,1.54)$ & 137.27 \\
\hline 11 & $4.40(5.80)$ & 71.02 \\
\hline 12 & & 64.54 \\
\hline $13 a$ & $2.81,(3.90)$ & 46.63 \\
\hline $13 b$ & $3.08,(3.90)$ & \\
\hline $14\left(\mathrm{CH}_{3}\right)$ & $0.76, \mathrm{~s}$ & 6.00 \\
\hline $15\left(\mathrm{CH}_{3}\right)$ & $1.03, \mathrm{~s}$ & 18.46 \\
\hline $16\left(\mathrm{CH}_{3}\right)$ & $1.83, \mathrm{~s}$ & 15.43 \\
\hline 17 & & 168.05 \\
\hline 18 & $5.89(11.50,1.80)$ & 119.90 \\
\hline 19 & $6.48(11.50,7.30)$ & 147.26 \\
\hline $20\left(\mathrm{CH}_{3}\right)$ & $2.17(1.80,7.30)$ & 15.65 \\
\hline
\end{tabular}

* Numbering of various atoms are given in Figure 2.

Significant increase in the sub $G_{0}$ population was observed in Trichothecinol-A treated cells in a time dependent manner. $500 \mathrm{nM}$ of Trichothecinol-A had $12.7 \%$ sub $\mathrm{G}_{0}$ population as compared to $3.88 \%$ in vehicle control in $12 \mathrm{~h}$. However, cells treated with 500 $\mathrm{nM}$ of Trichothecinol-A for $24 \mathrm{~h}$ resulted in an

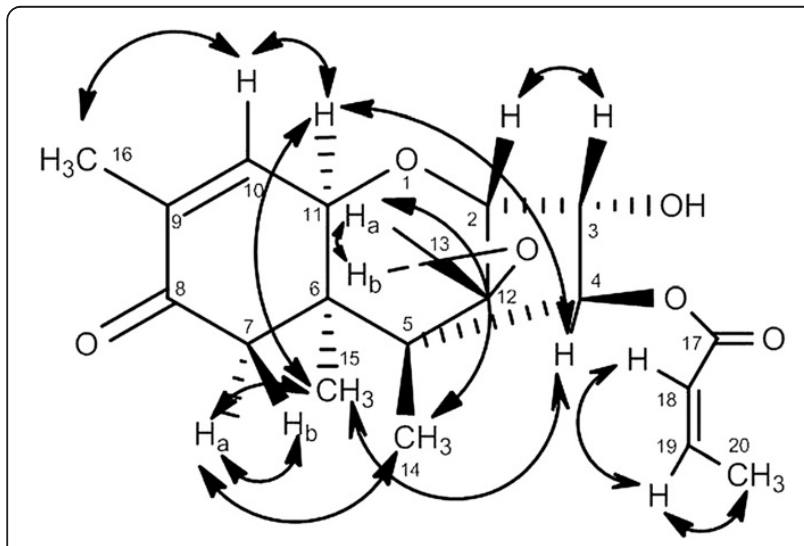

Figure 2 Selected nOe interactions of Trichothecinol-A (Mw: $348, \mathrm{C}_{19} \mathrm{H}_{24} \mathrm{O}_{6}$ ).
Table 2 MIC and IC 50 values of Trichothecinol-A

\begin{tabular}{|c|c|c|c|}
\hline Sr.No. & Organism $\$$ & $\begin{array}{l}\mathrm{IC} C_{50} \\
(\mu \mathrm{g} / \mathrm{mL})\end{array}$ & $\begin{array}{l}\text { MIC } \\
(\mu \mathrm{g} / \mathrm{mL})\end{array}$ \\
\hline 1 & Saccharomyces cerevisiae NCIM 3045 & 17.16 & 36 \\
\hline 2 & $\begin{array}{l}\text { Cryptococcus albidus var diffluens } \\
\text { NCIM } 3371\end{array}$ & 4.08 & 36 \\
\hline 3 & $\begin{array}{l}\text { Cryptococcus albidus var diffluens } \\
\text { NCIM } 3372\end{array}$ & 2.5 & 20 \\
\hline 4 & Fusarium oxysporum NCIM 1043 & 7.16 & $>100$ \\
\hline 5 & Aspergillus flavus NCIM 535 & 24.3 & $>100$ \\
\hline 6 & Trichoderma reesei NCIM 992 & 15 & 90 \\
\hline 7 & Penicillium expansum NCIM 939 & 6.61 & 50 \\
\hline 8 & Trichoderma viride NCIM 1051 & 36.6 & $>100$ \\
\hline 9 & Paecilomyces varioti NCIM 1217 & 8.69 & 70 \\
\hline 10 & Aspergillus niger NCIM 773 & 9.12 & $>100$ \\
\hline
\end{tabular}

increase of apoptotic fraction to $52.96 \%$ versus $16.68 \%$ in vehicle control.

Enhanced migratory capacity is one of the hall marks of highly invasive tumor cells. Inhibition of cancer cell migration could be an effective means of preventing cancer metastasis, thereby enabling confinement of primary tumors in manageable form, making surgical options more viable [15]. During opening phase of the metastatic cascade, cancer cells penetrate into surrounding tissues and blood vessels and it has been shown to be the rate limiting step in an experimental model [16]. Therefore, inhibition of the cell migration represents a potential therapeutic approach for the treatment of tumor metastasis. Here, we studied the inhibitory effect of Trichothecinol-A in MDAMB-231 cell migration at various concentrations. Percentage of wound closure was determined by the difference in area covered by migrated cells in control versus treated with Trichothecinol-A at 0 or $18 \mathrm{~h}$. The results show that the $500 \mathrm{nM}$ of Trichothecinol-A was able to inhibit wound closure by $50 \%$ where as 2.5 and $5 \mu \mathrm{M}$ concentrations of Trichothecinol-A inhibited migration up to $75 \%$ as compared to vehicle control (Figure $5 \mathrm{a} \& \mathrm{~b}$ ).

Because, the common approach of chemotherapy is to decrease the growth rate (cell division) of the cancer cells, the side effects are seen in bodily systems that naturally have a rapid turnover of cells including skin, hair, gastrointestinal and bone marrow. These healthy, normal cells also end up damaged by the chemotherapy program. Hence, it's reasonable to look out for compounds with antimetastatic activity which could be further developed as lead against cancer metastasis. As, Trichothecinol-A is showing promising antimetastatic activity against human breast carcinoma (MDA-MBA-231) and antiproliferative activity against skin carcinoma (B16F10) at nanomolar concentration, therefore, it can be used as scaffold in drug 


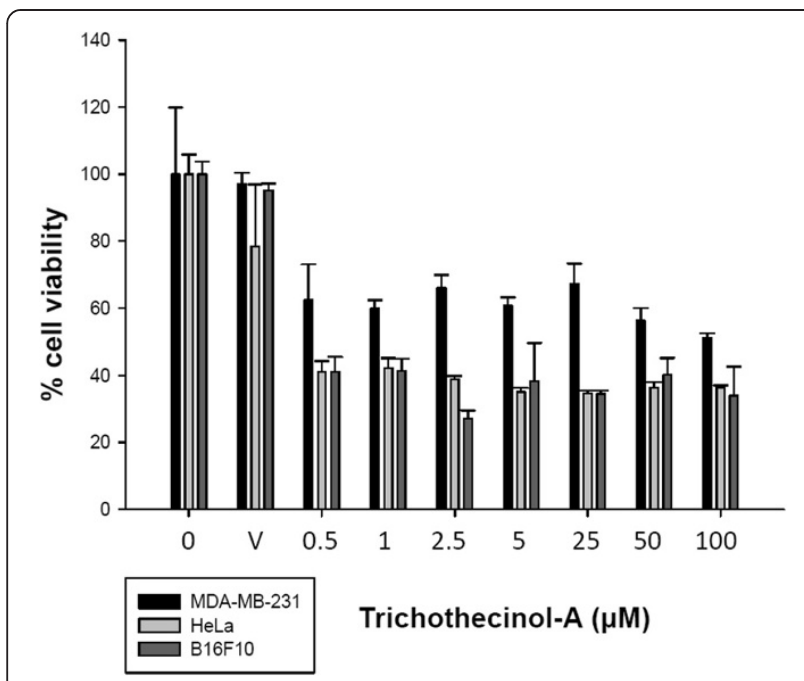

Figure 3 Effect of Trichothecinol-A on cancer cell proliferation. MDA-MB-231, HeLa and B16F10 cells were treated with DMSO as vehicle control and with Trichothecinol-A at varying concentrations from $0-100 \mu \mathrm{M}$ for $24 \mathrm{~h}$ and cell viability was determined by MTT assay.

discovery programme to synthesize analogues with better specificity and favourable pharmacological properties. Further efforts are needed to modify the compound to remove sites of non specific toxicity and understand the mechanism by which this compound inhibits cancer cell growth and migration.

\section{Materials and methods}

Isolation, purification, identification and screening of endophytic fungi for the production of Trichothecinol - A A total of 30 endophytic fungi (AAP-PS 1-30) were isolated from medicinal herb $P$. amarus as described elsewhere
[17-19]. Each fungal culture was checked for purity and transferred to agar slants by hyphal tip as well as single spore isolation method $[17,20]$. Production of Trichothecinol-A by endophytic fungi was studied by a two stage fermentation procedure [21]. The flasks containing MGYP media (Malt extract 0.3\%, Glucose 1\%, Yeast extract $0.3 \%$, Peptone $0.5 \%$ ) were inoculated with agar plugs of mycelium from 7 day old slants. The inoculated flasks were incubated at $28^{\circ} \mathrm{C}$ on rotary shaker at $180 \mathrm{rpm}$ for 6 days. These cultures were used as seed culture (first stage). For Trichothecinol $-\mathrm{A}$ production, $20 \mathrm{~mL}$ seed culture was transferred to $500 \mathrm{~mL}$ Erlenmeyer flask containing modified S7 medium [21]. The flasks were incubated at $28^{\circ} \mathrm{C}$ for 30 days as stationary culture (second stage). After incubation, the cultures were harvested and passed through sterile cotton to separate mycelial mat from culture filtrate. The culture filtrate was lyophilized and extracted thrice with equal volumes of ethyl acetate. The extracts were pooled and dried with anhydrous sodium sulphate and concentrated at $40^{\circ} \mathrm{C}$ under reduced pressure to yield crude extract. The antifungal activity and a method developed by Sorenson et. al. was used to detect Trichothecinol-A in crude extract [22]. The culture (AAP-PS-1) producing Trichothecinol-A was used for further studies.

\section{Identification of endophytic fungus producing \\ Trichothecinol-A by morphological and molecular methods}

Identity of endophytic fungal culture (AAP-PS-1) producing Trichothecinol-A was established by using morphological and molecular approaches. For studying the morphological features, the fungus was grown on potato dextrose agar (potato 25\%, dextrose $2 \%$, agar $2 \%$ ).

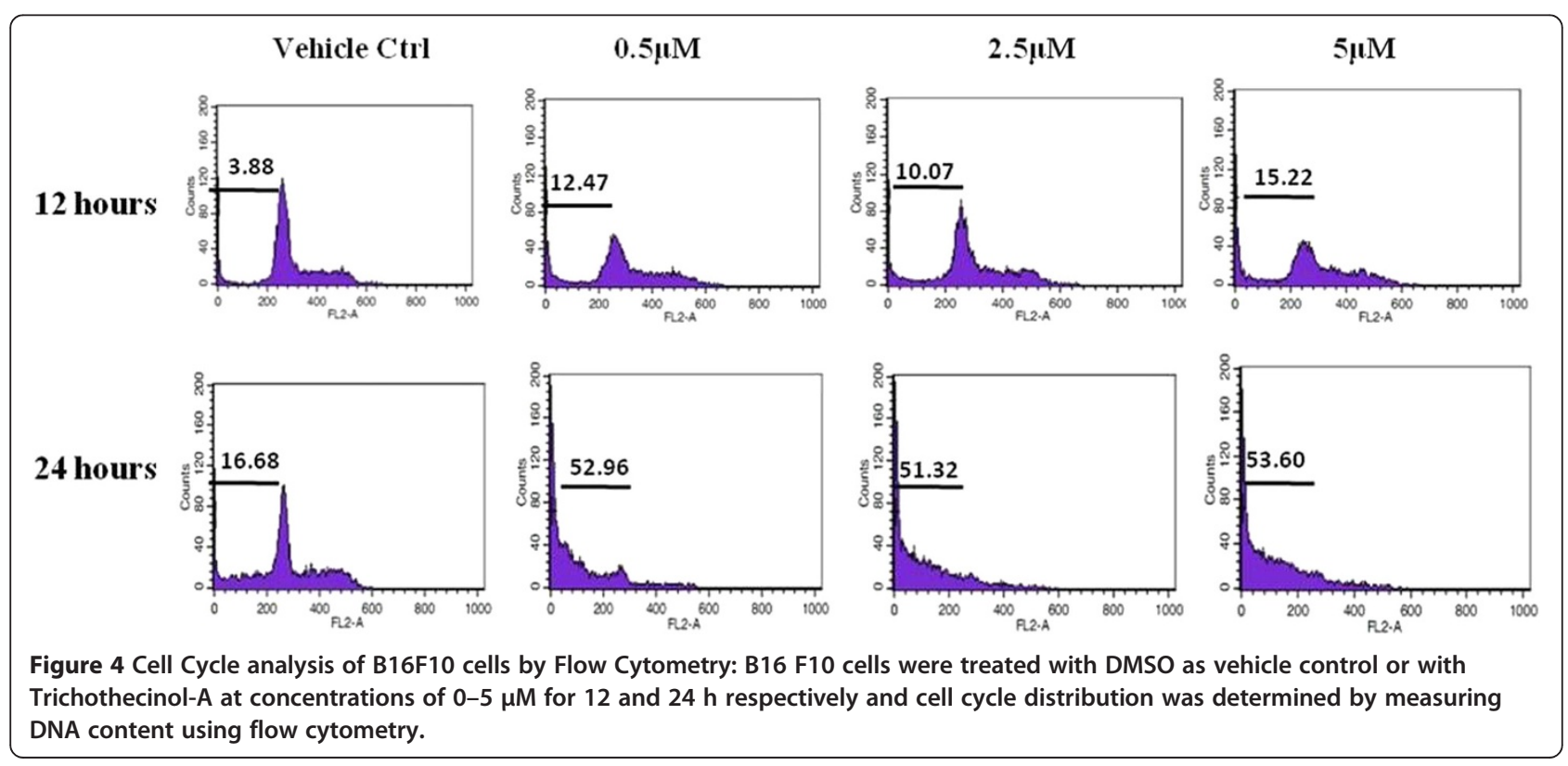



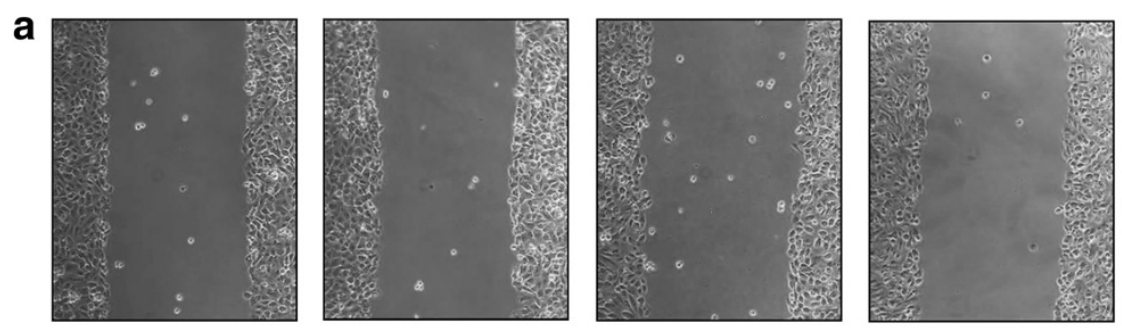

0 h

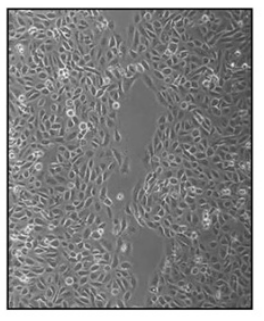

Vehicle

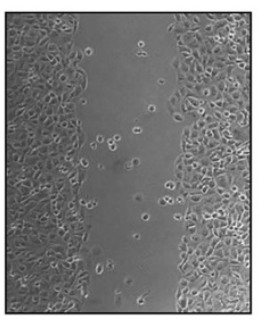

0.5

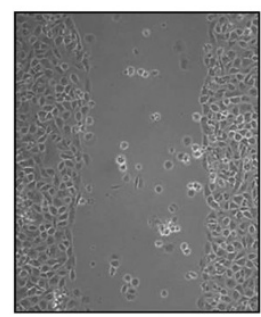

2.5

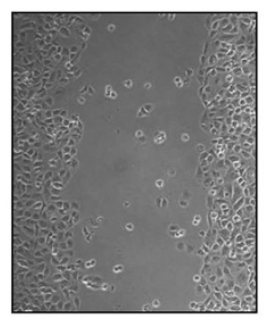

5

Trichothecinol-A $(\mu \mathrm{M})$

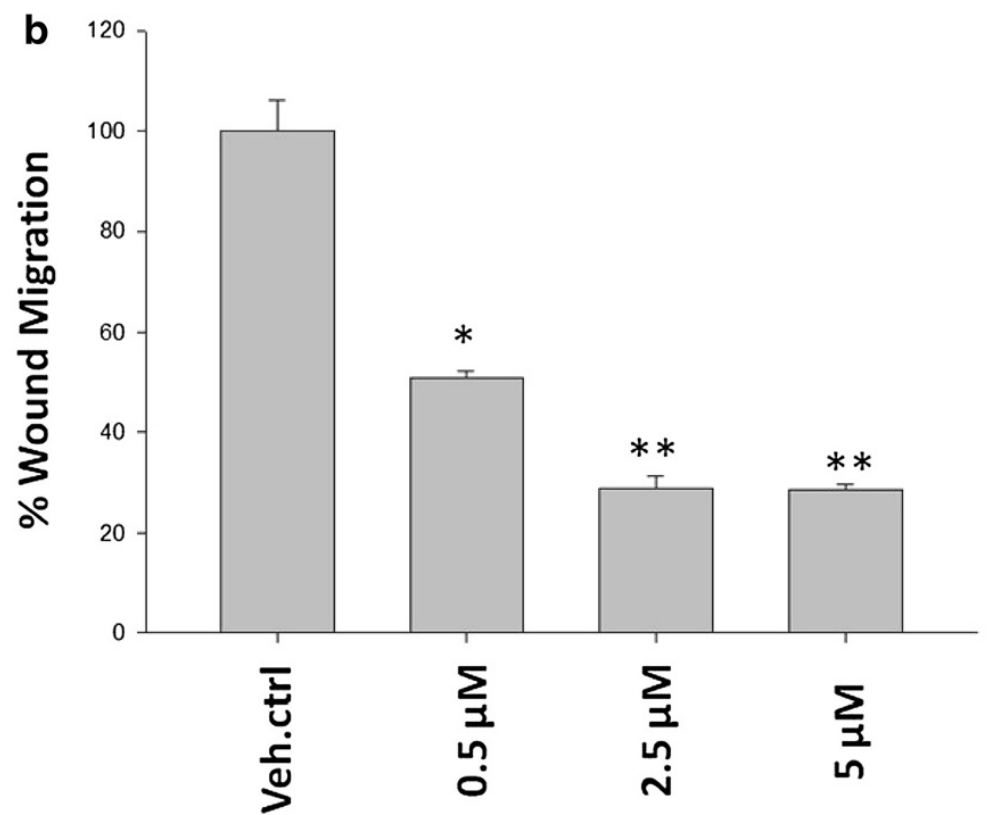

Figure 5 Inhibition of cell migration by Trichothecinol-A: a. MDA-MB-231 cells were treated with DMSO as vehicle and Trichothecinol-A at concentrations of $\mathbf{0 - 5} \boldsymbol{\mu m}$ for $\mathbf{1 8} \mathrm{h}$ and photographs were taken. $b$. The areas of migrated cells were quantified and represented as bar graph. ${ }^{*} p=.0013,{ }^{* *} p=.0003$ vs. vehicle control.

Morphological characteristics of the fungus like mycelia, conidiophores and conidia were microscopically studied (Carl Ziess Axiovert 25 Inverted microscope and Nikon Eclipse E200). The genomic DNA was isolated by salting out method with little modification [23]. Sonication for a period of $5 \mathrm{~min}$ was done before lysozyme treatment. ITS region of genomic DNA was amplified using ITS1 TCCGTAGGTGAACCTGCGG (forward) and ITS4 TCCTCCGCTTATTGATATGC (reverse) primers. PCR products were eluted from agarose gel by protocol described in Axygen ${ }^{\mathrm{T} \omega}$ gel elution kit, Biosciences USA. The purified PCR product was ligated with pGEM-T vector and transformed into competent E.coli XL-1 cells [24]. Plasmid containing the insert was isolated using alkaline lysis method [24]. The cloned fragments were sequenced using Sangers dideoxy method using ABI prism big dye terminator cycle sequencing kit from ABI system [25]. The sequence obtained was further analysed for its homology by using online tool nucleotide BLAST. The multiple sequence alignments were carried out using 
CLUSTAL-W and phylogenetic inferences were obtained using the maximum-likelihood method within MEGA program. The bootstrap of consensus tree was inferred from 500 replicates. The evolutionary distances were computed using the Kimura2 parameter. All positions containing gaps and missing data were eliminated from the dataset (Complete deletion option). Acremonium strictum were used as an out-group.

\section{Purification and quantification of Trichothecinol-A}

Trichothecinol-A was purified using preperative TLC and RP-HPLC. TLC plates coated with $0.5 \mathrm{~mm}$ thickness of silica were used for preparative TLC. Approximately $0.5 \mathrm{~mL}$ of crude sample dissolved in methanol was loaded on to plate and developed in hexane: ethyl acetate (2:1) solvent system. The developed plates were air dried and exposed to iodine vapours. Individual bands were scrapped, eluted with ethyl acetate, concentrated in vacuo and tested for antifungal activity against Aspergillus niger by agar well diffusion method. Out of eight bands, second and fifth band showed good antifungal activity. The second band was further processed for purification by analytical RP HPLC. HPLC analysis was performed on a Waters model using a $\mathrm{C}_{18}$ symmetry pack column with the flow rate of $0.5 \mathrm{~mL} / \mathrm{min}$ and eluted with a 40 minutes gradient of water: actonitrile (95: 5). The Trichothecinol-A was detected by a dual mode wavelength detector set at $220 \mathrm{~nm}$ and $240 \mathrm{~nm}$.

\section{Quantification of Trichothecinol-A by HPLC}

Stock solution of different concentrations $(1 \mathrm{mg} / \mathrm{ml}$, $3 \mathrm{mg} / \mathrm{ml}, 5 \mathrm{mg} / \mathrm{ml}$ and $10 \mathrm{mg} / \mathrm{ml}$ ) of a purified Trichothecinol-A was prepared in HPLC grade acetonitrile. $10 \mu \mathrm{l}$ of each stock solution was injected in HPLC to generate a standard graph of peak area v/s concentration. Then, the known volume of $(10 \mu \mathrm{l})$ crude dissolved in HPLC grade acetonitrile containing unknown concentration of Trichothecinol-A was analysed by HPLC and the peak area of Trichothecinol-A containing peak was compared to standard graph to calculate its concentration.

\section{Complete characterization of Trichothecinol-A}

UV-visible spectroscopy measurements were carried out on Jasco dual beam spectrophotometer (model V- 570) operated at resolution of $1 \mathrm{~nm}$. Molecular mass of the compound was determined by M/S Applied Biosystems API QSTAR pulsar (ESI-MS) mass spectrometer. HRMS analysis was carried out using mass spectrometry instrument (model - Autoconcept) by direct injection probe with resolving power of 6000. FTIR spectroscopy measurements of purified compound taken in Kbr pellet were carried out using a Perkin-Elmer spectrum one instrument. Spectrometer was used in the diffuse reflectance mode of resolution $2 \mathrm{~cm}^{-1}$. All the NMR measurements were carried out on Bruker AV 500 spectrometer operating at $500 \mathrm{MHz}$ and $125 \mathrm{MHz}$, respectively for ${ }^{1} \mathrm{H}$ and ${ }^{13} \mathrm{C}$. $\sim 10 \mathrm{mg}$ of the compound was dissolved in $\mathrm{CDCl}_{3}$ in a $5 \mathrm{~mm}$ NMR tube and the ${ }^{1} \mathrm{H},{ }^{13} \mathrm{C}$, COSY, NOESY, TOCSY, ${ }^{13} \mathrm{C}-{ }^{1} \mathrm{H}$ HSQC and ${ }^{13} \mathrm{C}-{ }^{1} \mathrm{H}$ HMBC experiments were performed under standard conditions using a $5 \mathrm{~mm}$ $\mathrm{BBFO}$ probe at ambient temperature $\left(\sim 25^{\circ} \mathrm{C}\right)$. Chemical shifts in the ${ }^{1} \mathrm{H}$ spectra were referenced to residual $\mathrm{CHCl}_{3}$ peak $(7.26 \mathrm{ppm})$, while ${ }^{13} \mathrm{C}$ spectra were referenced to $\mathrm{CDCl}_{3}(77.0 \mathrm{ppm})$.

\section{Antifungal assay}

The purified compound was analyzed for antifungal activity against different plant pathogenic, saprophytic fungi and yeast. Antifungal assay was performed in microtiter plates as reported earlier [26,27]. Fungal spores were removed from a 4 days old culture, transferred to YM broth (Glucose 1\%, Malt extract $0.3 \%$, Yeast extract $0.3 \%$ ) and adjusted to $2 \times 10^{5}$ spores or cells $/ \mathrm{mL}$. The compound was diluted in DMSO to get desired concentrations. $50 \mu \mathrm{L}$ aliquots of spores were mixed with different concentrations of compounds (10 to $100 \mu \mathrm{g} / \mathrm{mL}$ in $10 \mu \mathrm{L}$ of DMSO). Final volume was adjusted by adding $140 \mu \mathrm{L}$ YM media. Total assay volume was $200 \mu \mathrm{L}$. The plates were incubated at $28^{\circ} \mathrm{C}$ for $48 \mathrm{~h}$.

\section{OD 600 measurements}

The OD 600 measurements were carried out on microtiter plate reader (Bio-Rad xMark). The MIC was determined as the lowest concentration of Trichothecinol-A that completely inhibits visible growth of the microorganism. The dose response curves were obtained by plotting concentration of compound $\mathrm{v} / \mathrm{s} \%$ growth inhibition. The $\mathrm{IC}_{50}$ values were determined as the concentration of Trichothecinol-A that could show 50\% of maximum inhibition.

\section{Cell culture and reagents}

Human breast adenocarcinoma (MDA-MB-231), human cervical cancer (HeLa) and murine melanoma (B16F10) cell lines were obtained from American Type Culture Collection and were grown in L-15, DMEM and RPMI media respectively, supplemented with $10 \%$ fetal bovine serum and $100 \mathrm{U} / \mathrm{mL}$ Penicillin and Streptomycin (Invitrogen). All cells were grown in humidified atmosphere with or without $5 \% \mathrm{CO}_{2}$ and $95 \%$ air at $37^{\circ} \mathrm{C}$. Tetrazolium dye and Propidium Iodide was purchased from Sigma.

\section{Cell viability assay}

MDA-MB-231, HeLa and B16F10 cells $\left(2 \times 10^{4}\right)$ were seeded in 96 well plates. Cells were treated with Trichothecinol-A for $24 \mathrm{~h}$ with indicated concentration. 
Treatment was terminated by removing media and MTT [3-(4,5-dimethylthiazol-2yl)-2,5-diphenyl tetrazolium bromide] $(0.5 \mathrm{mg} / \mathrm{ml})$ was added. After $4 \mathrm{~h}$, crystals were dissolved in isopropanol and $\mathrm{A}_{570}$ was recorded.

\section{Flow cytometry analysis}

Flow cytometry experiments were performed as described earlier [28]. Murine melanoma B16F10 cells were treated with indicated concentrations of TrichothecinolA in RPMI media supplemented with $10 \%$ fetal bovine sera for 12 and $24 \mathrm{~h}$. DNA analysis was done and cell undergoing apoptosis were determined following propidium iodide staining (FACS Calibar, Becton Dickinson).

\section{Wound assay}

Wound assay was performed with post confluent MDAMB-231 cells as described [29]. Briefly, uniform sized wounds were made. MDA-MB-231 cells were treated with $2.5 \mu \mathrm{M}$ of Trichothecinol-A. DMSO was used as vehicle control. After $18 \mathrm{~h}$, photographs were taken and the area of migrated cells was quantified using Image Pro Plus 6.0 software (Nikon).

\section{Statistical analysis}

The data reported in cytotoxicity and cell migration experiments are expressed as mean \pm S.E. Statistical differences were determined by Student's $t$ test. The $\mathrm{p}$ value $<0.05$ was considered significant.

\section{Conclusion}

We for the first time have isolated a sesquiterpene viz. Trichothecinol-A produced by an endophytic fungus Trichothecium sp. isolated from medicinal herb Phyllanthus amarus. The compound was purified and characterized by using different chromatographic and spectroscopic techniques. Being non proteinaceous in nature, this compound holds the promise of potent antiproliferative and most importantly antimetastic lead, if suitably modified by employing combinatorial chemistry approaches to enhance its drug like properties. Trichothecinol-A exhibits appreciable antimetastatic activity against human breast carcinoma (MDA-MBA-231) and antiproliferative activity against skin carcinoma (B16F10) at nanomolar concentrations. Also, Trichothecinol-A showed good antifungal activity against Cryptococcus albidus var diffluens (NCIM 3371 and 3372) and Penicillium expansum (NCIM 939). Therefore, the above compound could be used as scaffold in drug discovery programmes to synthesize effective and more specific analogues which can be further developed as drugs. Further studies are required to understand the mechanism by which this compound inhibit cancer cell growth and metastasis.

\section{Additional file}

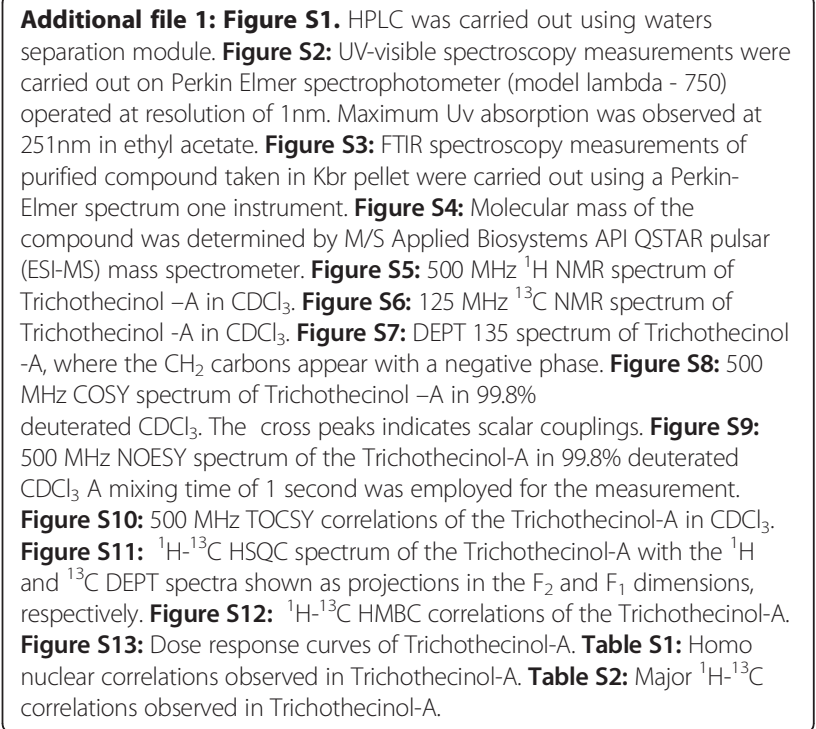

\section{Competing interests}

The authors declare that they have no competing interests.

\section{Authors' contributions}

RT isolated, purified and characterized the compound and helped in preparing the manuscript. PA assisted during antifungal assay. DP and PRR helped in evaluation of NMR measurements. RR, GS and GK carried out cytotoxicity experiments with cell lines. AA conceived the study, designed the experiments and wrote the manuscript. All authors have read and approved the final manuscript.

\section{Acknowledgments}

R T thanks Department of Biotechnology, Government of India for research scholarship. AA thanks the Department of Biotechnology, Government of India (New Delhi) for the Tata Innovation Fellowship award and financial support through BSC0112 CSIR. We thank Dr. Sujata Biswas and Mr. Senthilkumar for HRMS analysis at the Centre for Materials Characterisation, CSIR-National Chemical Laboratory (NCL), Pune (Maharashtra, India). The National Collection of Industrial Microorganisms, CSIR-NCL, Pune (India) duly acknowledged for providing fungal and yeast cultures for antifungal assay. The authors also thank Dr. H.B Borate, Department of Organic Chemistry Division, CSIR-NCL, Pune (India) for his fruitful suggestions and Mrs. Shantha Kumari, Center for Materials Characterization (CMC), CSIR-NCL, Pune for assistance regarding ESI-MS and MS/MS measurements.

\section{Author details}

'Division of Biochemical Sciences, CSIR-National Chemical Laboratory, Dr. Homi Bhabha Road, Pune 411008 , India. ${ }^{2}$ Central NMR facility, CSIR-National Chemical Laboratory, Dr. Homi Bhabha Road, Pune 411008, India. ${ }^{3}$ National Centre for Cell Science, NCCS Complex, Pune University Campus, Pune 411007, India.

Received: 30 December 2013 Accepted: 18 March 2014 Published: 28 March 2014

\section{References}

1. Tan RX, Zou WX: Endophytes: a rich source of functional metabolites. Nat Prod Rep 2001, 18:448-459.

2. Gunatilaka AAL: Natural products from plant-associated microorganisms: distribution, structural diversity, bioactivity, and implications of their occurrence. J Nat Prod 2006, 69:509-526.

3. Zhou L, Zhao J, Xu L, Huang Y, Ma Z, Wang JJW: Antimicrobial compounds produced by plant endophytic fungi. In Fungicides: Chemistry. New York: Publishers; 2009:91-119. 
4. Bretz M, Beyer M, Cramer B, Knecht A, Humpf HU: Thermal degradation of the Fusarium mycotoxin deoxynivalenol. J Agric Food Chem 2006, 54:6445-6451

5. Hazel CM, Patel S: Influence of processing on trichothecene levels. Toxicol Lett 2004, 153:51-59.

6. Middlebrook JL, Leatherman DL: Specific association of T-2 toxin with mammalian cells. Biochem Pharmacol 1989, 38:3093-3102.

7. Wannemacher RW, Winer SL: Trichothecene Mycotoxins. In Medical Aspects of Chemical and Biological Warfare. Edited by Sidell RR, Takafuji ET, Franz DRE. Washington DC: Office of the Surgeon General at TMM Publications; 1977:655-676.

8. Bamburg J: Biological and biochemical actions of trichothecene mycotoxins. Prog Mol Subcell Biol 1983, 8:41-110.

9. Konishi K, lida A, Kaneko M, Tomioka K, Tokuda H, Nishino H, Kumeda Y: Cancer preventive potential of trichothecenes from Trichothecium roseum. Bioorg Med Chem 2003, 11:2511-2518.

10. Chopra RN, Nayar SL, Chopra IC: Glossary of Indian Medicinal Plants. National Institute of Science Communication and Information Resources, Council of Scientific \& Industrial Research: New Delhi, India; 1956.

11. Kirtikar KR, Basu BD: Indian Medicinal Plants. 2nd edition. Uttranchal, India: Oriental Enterprises; 2001:3068-3069.

12. Reddy KR: Folk medicine from Chittoor district, Andhra Pradesh, India, used in the treatment of jaundice. Int J Crude Drug Res 1988, 26:137-140.

13. Satyavati GV, Gupta AK, Tandon N: Medicinal plants of India. New Delhi: Indian Council of Medical Research; 1987:405-411.

14. Barnett H: Illustrated genra of imperfect fungi. Secondth edition. Minneapolis: Burgess publishing company; 1969:66-67.

15. Hedley BD, Winquist E, Chambers AF: Therapeutic targets for antimetastatic therapy. Expert Opin Ther Targets 2004, 8:527-536.

16. Wyckoff JB, Jones JG, Condeelis JS, Segall JE: A critical step in metastasis: in vivo analysis of intravasation at the primary tumor. Cancer Research 2000, 60:2504-2511.

17. Ahmad A: Investigations on the grassy-shoot disease of lemongrass (Cymbopogon flexuosus) and characterization of toxic metabolites produced by the causal agent Balansia sclerotica. Lucknow: University of Lucknow; 1991.

18. Bills GF, Redlin SC, Carris LM: Endophytic fungi in grasses and woody plants: systematics, ecology, and evolution. In Isolation and analysis of endophytic fungal communities from woody plants. Edited by Redlin SC, Carris LM. St Paul: American Phytopathological Society Press; 1996:31-65.

19. Janardhanan KK, Ahmad A, Gupta ML, Hussain A: Grassy- shoot, a new disease of lemongrass caused by Balansia sclerotica (Pat) Hohnel. J Phytopathology 1991, 133:163-168.

20. Strobel GA, Hess WM, Ford E, Sidhu RS, Yang X: Taxol from fungal endophytes and the issue of biodiversity. J Ind Microbiol 1996 17:417-423.

21. Stierle A, Strobel G, Stierle D: Taxol and taxane production by Taxomyces andreanae, an endophytic fungus of Pacific yew. Science 1993, 260:214-216.

22. Sorenson WG, Sneller MR, Larsh HW: Qualitative and quantitative assay of trichothecin: a mycotoxin produced by Trichothecium roseum. Appl Microbiol 1975, 29:653-657.

23. Neumann B, Pospiech A, Schairer HU: Rapid isolation of genomic DNA from gram-negative bacteria. Trends Genet 1992, 8:332-333.

24. Sambrook J, Fritsch EF, Maniatis T: Molecular Cloning, Volume 68. New York: Cold Spring Harbor Laboratory Press; 1989:1232-1239.

25. Sanger F, Nicklen S, Coulson AR: DNA sequencing with chain terminating inhibitors. Proc Natl Acad Sci USA 1977, 74:5463-5467.

26. Cavalieri SJ: Manual of Antimicrobial Susceptibility Testing. Washington DC: American Society for Microbiology; 2005:53-62.

27. Amsterdam D: Susceptibility testing of antimicrobials in liquid media. In Antibiotics in Laboratory Medicine, Volume 4. Edited by Williams LV. Baltimore: Wilkins; 2005:61-143.

28. Valli C, Paroni G, Di Francesco AM, Riccardi R, Tavecchio M, Erba E, Boldetti A, Gianni' M, Fratelli M, Pisano C, Merlini L, Antoccia A, Cenciarelli C, Terao
M, Garattini E: Atypical retinoids ST1926 and CD437 are S-phase-specific agents causing DNA double-strand breaks: significance for the cytotoxic and antiproliferative activity. Mol Cancer Ther 2008, 7:2941-2954.

29. Chakraborty G, Jain S, Kale S, Raja R, Kumar S, Mishra R, Kundu G: Curcumin suppresses breast tumor angiogenesis by abrogating osteopontininduced VEGF expression. Mol Med Rep 2008, 1:641-646.

doi:10.1186/2043-7129-2-8

Cite this article as: Taware et al:: Isolation, purification and characterization of Trichothecinol-A produced by endophytic fungus Trichothecium sp. and its antifungal, anticancer and antimetastatic activities. Sustainable Chemical Processes 2014 2:8.

Publish with ChemistryCentral and every
scientist can read your work free of charge
"Open access provides opportunities to our
colleagues in other parts of the globe, by allowing
anyone to view the content free of charge."
W. Jeffery Hurst, The Hershey Company.
- available free of charge to the entire scientific community
- peer reviewed and published immediately upon acceptance
- cited in PubMed and archived on PubMed Central
- yours - you keep the copyright
submit your manuscript here:
http://www.chemistrycentral.com/manuscript/

